\title{
Determination and Legal Application of Internet Monopoly
}

\author{
Ruixin Xiong ${ }^{1, *}$ \\ ${ }^{1}$ International Law Academy, East China University of Political Science and Law, Shanghai 201600, China \\ "Corresponding author. Email: 15079302069@163.com
}

\begin{abstract}
This article is about antitrust law and its application and implementation in the Internet domain. Based on the above arguments, it can be seen that monopolization in the digital market is almost inevitable due to the "non-competitive" nature of information products without the involvement of the "visible hand" of control. Thus, the issue of determining monopolistic behavior in the Internet field deserves further investigation.
\end{abstract}

Keywords: determination, legal, internet monopoly

\section{INTRODUCTION}

In the contemporary era of globalization, a highly concentrated market economy as well as the deepening transnationalization and digital informatization, are becoming more and more prominent. Multinational corporations running digital platforms enable the information exchange between customers and operators and simultaneously collect and analyze the data. A series of new problems have consequently emerged as a result of the rapid development of technology. This paper begins with the case of The U.S. Government sues Google, with the intention of analyzing the causes of the monopoly problem in the Internet sector and the contradiction between the imperfect legislation and the application of the law through the study of the "monopoly allegations" of the technology giants in the field of digital technology. This article discusses three of the main causes of the monopoly in the Internet domain: Bilateral markets, network effects, lock-in effects and what they lead to, The winner-takes-all, a common phenomenon in the Internet industry.

\section{THE INTERNET MONOPOLY DIMENSION OF THE U.S. SUIT AGAINST GOOGLE}

On October 21, the U.S. Department of Justice formally announced that a civil antitrust lawsuit against Google will be filed in the District Court of Columbia, alleging that Google abused its dominant market position to undercut competitors and thereby maintain its monopoly in the field. The U.S. government has suggested that Google has created a self-reinforcing area of dominance by paying handset makers significant sums of money to set Chrome as the default browser and to build in a Google search engine. Previously, the U.S. Department of Justice had been conducting an antitrust investigation against Google for more than a year. Since 2017, the European Union has brought at least three charges against Google, and the built-in browser and search engine were an illegal monopoly on Android devices. The cause of prosecution in the latest EU ruling also includes Google's efforts to strengthen its monopoly in the advertising market by impeding competition through exclusive agreements with online companies. At the same time, a number of larger technology companies are also under investigation.

Back in 1998, the U.S. government charged Microsoft with monopolization and unlawful use of a dominant market position to engage in misconduct, alleging abuse of its monopoly power over Intel's chipbased PC operating system and Web browser. In 2004, the European Union similarly fined Microsoft for unlawful use of its monopoly to bundle media players and software. The Microsoft of that time is analogous to the Google of today, and it is because the ruling and enforcement of the ruling on Microsoft has largely weakened its monopoly power in the market that Google has risen to power and won the competition in web browsers.

Nevertheless, in the meantime, Kent Walker, Google's chief legal officer, said in a statement that the lawsuit was deeply flawed. "People use Google because they choose to - not because they're forced to or because they can't find alternatives," he said. "Like countless other businesses, we pay to promote our services, just like a cereal brand might pay a supermarket to stock its products at the end of a row or on a shelf at eye level." And Google has appealed to the European Union's decision, with the latest ruling coming in 2021 . 
This series of prosecutions of technology giants essentially exemplifies the growing problem of monopolization in this area and the determination of monopolistic behavior under the antitrust laws of various countries. The U.S. government argued that Google's anti-competitive practices had a detrimental effect on competition and consumers, and that it had entered into a series of exclusive agreements that deprived its competitors of "critical distribution, scale, and product awareness. In Google's case, however, it was merely engaging in legitimate business practices, and its "monopoly position" was based on consumers' own choice of superior products.

Thus, the line between commercial behavior and monopolistic behavior is not clear-cut, but rather ambiguous and indistinguishable. Particularly with the rapid development of science and technology, the old laws are not able to take into account the new fields that are emerging, and new problems are emerging. Based on this case, the U.S. government called for a major revision of the antitrust law, and the European Union passed the Data Communication Restriction Act with a large number of votes, so it can be inferred that the current market is not friendly to the technological innovation and competitiveness of ordinary enterprises.

\section{INTERNET MONOPOLY IN-DEPTH STUDY}

\section{A. Causes of monopoly in the Internet}

The development of human society has entered the era of the digital economy, and the advent of big data has also highlighted the bilateralization of the Internet industry. The famous economist David S. Evans has reviewed the basic economic model of the Internet industry in a paper and concluded that Internet companies usually use cross-subsidization strategies, and use advertising revenue to support business development. For example, a search engine such as Google provides users with a free information retrieval platform in exchange for clicks and data, as well as a platform for other business operators to place advertisements, and the higher the number of clicks, the higher the advertising revenue it can charge. The more accurate it is. Thus, the bilateral market is data-centric, with users participating in the generation of relevant data-based content. Internet search engines providing search services can also profit. [3]

In fact, these giants, located in bilateral markets, act more like bridges between groups of people with mutual needs, connecting them through data analytics to enhance and demonstrate their value. In this process, network effects (as an externality) play an important role in their market share acquisition. At the same time, when users of an Internet service use the same platform for a long period of time, the data stored in the storage generates significant sunk costs for learning and migration - the former refers to the long period of time needed for consumers to learn or adapt to the service environment, while the latter refers to the long period of time required if users accumulate a large amount of data on a platform. When consumers choose to transfer their personal data to other homogeneous service platforms, their personal data needs to be collected again and cannot be moved with them, and the search results they can get will certainly not be as good as those of the former platform they have already used, which will result in high switching costs, thus significantly harming consumers' service experience and increasing the competitive advantage of the former platform. In summary, this creates an economic "lockin effect".

To summarize, the economic phenomena of bilateral markets, network effects, and lock-in effects have led to the "winner-takes-all" phenomenon that is so common in the Internet industry, and to some extent, due to the natural "non-competitive" nature of information products, there is no "winner-takes-all" market in the absence of a "winner-takes-all" market. Monopolization in the digital marketplace is almost inevitable, given the involvement of the "visible hand" in the manipulation. As a direct beneficiary of these effects, Google's monopoly of the online search and digital advertising markets is very likely. [4]

\section{B. Internet monopoly determination}

While monopolies undoubtedly harm competition, determining monopolistic behavior is equally difficult. As Google's defense to the U.S. government's charge, the definition of its subjective purpose is necessarily ambiguous because of the blurred line between ordinary commercial conduct and abuse of dominance.

According to Article 102 of the EU Directive, in the European Union, the determination of monopolistic conduct by a firm that abuses its dominant market position is based on whether the firm has obtained a relevant dominant market position, whether the firm has abused its dominant market position, and whether the abuse of its dominant market position has undermined market competition.

However, in the context of the digital economy, it is difficult to define the relevant market in the first place. Secondly, Article 102 TFEU refers to a dominant position in relation to the economic strength of an undertaking, which means that the undertaking is able to prevent competitors from competing effectively in the relevant market by granting it a substantial degree of power. [5] Thus, Google's response to the EU's monopoly charges of violating European competition law, etc., is somewhat stronger: "The search service provided by the search engine itself is neutral, and the display and ranking of search results is objective and natural. In the era of big data, the objectivity of the data 
analysis algorithms used by Internet companies is difficult to judge, because the parameters that make up the algorithms themselves are written in such a way that they inevitably incorporate the values of the constructors themselves. The question ultimately comes back to the "subjective determination of intent" that was originally proposed.

Enterprises engage in commercial behavior itself is profit-oriented in nature, and through a series of effective means to maximize their own value and enhance market competitiveness. As mentioned above, in the digital economy of the Internet, natural monopoly is the inevitable result of market development, so to analyze whether Google's behavior constitutes "monopoly and abuse of market dominance" from the perspective of antitrust law, in addition to the objectivity of the algorithm itself, we should also focus on whether there are subjective factors leading to human error. It is also important to determine whether the exclusion of the natural order of the market will cause any disturbance to competitors and the competitive order of the market. The analysis of the facts will return to the inference of the subjective will of the behavior. Due to the natural tendency of the digital economy market in the Internet field to monopolistic phenomena, the decision should be made in favor of the competitors of giant enterprises, so as to ensure the relative fairness of the market level and maintain a good competitive order.

\section{Antitrust laws applicable in the Internet sector}

In addition to the determination of whether a specific action should be classified as a monopolistic act of abuse of dominant market position, with the rapid progress of economic globalization and the advent of the big data era, a large number of cases are no longer limited to a single country, but have the characteristics of involving many countries and a wide range of interests. Law should be applied and how to deal with them becomes a new challenge.

There is a substantial lack of enforceable international competition regulation in the field of international antitrust, however, at the international law level, except for the EC competition law, there is a virtual absence of multilateral rules on international monopoly regulation. [6] Most of the relevant treaties are bilateral agreements. To a certain extent, bilateral agreements can harmonize the application of international antitrust laws, avoid some extraterritorial application conflicts, and relatively strengthen the regulation of international monopoly behavior, but at the same time, they have strong limitations, most of the existing bilateral treaties are very limited in content and most of them are procedural issues. Bilateral treaties have few specific normative provisions for resolving conflicts and do not involve specific substantive rules for international monopolies. In addition, bilateral treaties cover only a small number of developed countries and do not cover a wide range of areas, and their effects are only applicable to the two contracting parties.

As for the extraterritorial application of the domestic antitrust law, the "reasonableness principle", i.e., "no unreasonable harm to the interests of the arbitrary party" and "domestic interests outweigh foreign interests", is generally followed. "However, the Sherman Act of the United States has run into many obstacles. Because domestic law is basically to protect domestic interests, the country's profit-seeking nature leads to the enactment and implementation of the law will give priority to its own country, so inevitably narrow in extraterritorial application. It is difficult to achieve absolute neutrality and impartiality, as pointed out by Professor Tuojun: "countries are generally opposed to monopolistic and restrictive behavior in the domestic market, but the Sherman Act is not a good example. The competition of domestic enterprises in international markets is often supported on the basis of self-interest.[7] As a result, the extraterritorial application of the law is prone to conflict, thus seriously undermining the intended effect of international monopoly regulation.

Therefore, as the U.S. government has called for in the case against Google, the filling, improvement and uniform application of international antitrust law is imminent. However, how to legislate and how to apply the law will become a new challenge. At present, countries still have differences on the way to reach a common ideological basis for antitrust, but progress can be seen even though the development process is slow. Before reaching a unified international antitrust legislation and a neutral third-party organization to ensure the implementation of the law, countries should first strengthen the norms and control of the extraterritorial application of domestic laws, and improve the use of the principle of reasonableness to avoid conflicts and confrontation caused by the arbitrary application of domestic laws. It is important to strengthen the efficiency of the use of international antitrust regulations and strengthen international antitrust cooperation. In addition, multilateral cooperation and communication on the regulation of international monopoly behavior under the WTO framework should be strengthened to encourage developing countries to participate in international antitrust cooperation, but at the same time, it is necessary to be cautious of possible international optimism behavior.

Assuming that the international anti-monopoly legislation has been basically perfected, but if a unified enforcement standard has not yet been formed, its incomplete and differential implementation will 
inevitably lead to a large number of enterprises flowing into relatively favorable countries, so that the countries that have left measures to implement anti-monopoly measures will get short-term economic development. The international community needs not simply "unified antitrust legislation", but a unified application standard and legal interpretation in the field of antitrust. We should promote the establishment of a neutral global antitrust organization, take corresponding measures to prevent national speculation, and implement antitrust as a unanimous goal.

\section{CONCLUSION}

With the advent of the big data era and the rapid development of the digital economy, the high-tech and Internet industries have shown their reliance on complex technology spillovers, network effects, economies of scale, standardization and compatibility, posing many new challenges to antitrust enforcement. The exclusion or restriction of competition by many market entities is likely to be difficult to detect due to the hidden nature or weakness of traditional monopoly behavior, and even if it is discovered, it is difficult to identify and punish it appropriately according to the traditional methods. At the same time, many countries are responding to the situation, as evidenced by the investigation and prosecution of Internet industry giants such as Google. In dealing with the monopoly problem in the digital technology field, we should fully recognize its characteristics, analyze the anti-monopoly regulation in specific cases combined with the characteristics of the Internet industry, actively promote the improvement and implementation of international anti-monopoly law, and look at the related issues from the perspective of development, and strengthen international cooperation to build a unified goal of maintaining the international market competition order.

\section{References}

[1] Brent Kendall\&Rob Copeland: Justice Department Hits Google With Antitrust Lawsuit; Suit follows lengthy investigation into company's dominance of search traffic and effect on competition. The Wall Street Journal Online.[2020-10-20] [1/5]

[2] David S. Evans, "The Economics of the Online Advertising Industry", 7 Review of Network Economics 1 [2008]

[3] Kou Yunmei, Ren Chao. Antitrust Regulation of Market Dominance Abuse by Internet Enterprises in the Digital Economy: The Case of the EU Google Case [J]. Hainan Finance, 2020(5): 42-50.

[4] See Danny Sullivan, "Google Still World's Most Popular Search Engine By Far, But Share Of Unique Searchers Dips Slightly", Search Engine Land 2013, http://searchengineland.com/googleworlds-most-popular-search-engine-148089, accessed9 July 2016;Matt Rosoff, "Here's How Dominant Google Is In Europe", Business Insider 2016, http://uk.businessinsider.com/heres-howdominant-google-is-in-europe-2014-11?r=US\&IR=T, accessed 9 July 2016.
[5] Case C-27/76, United Brands and United Brands Continental v Commission , EU:C:1978:22, paragraph 65; Case 85/76, Hoffmann-La Roche v Commission. EU:C:1979:36, paragraph 38.

[6] Yu You: "On the Internationalization of Monopoly and the Transformation of the Anti-Monopoly Legal System", in Economic Law from Theory, 2008, Vol. 1, No. 14, P81-95.

[7] Qiu Duojun, "The Synchronous Evolution of Markets, Regulatory Mechanisms, and Law: A Review and Prospect at the Turn of the Century," in Qiu Duojun (ed.), Economic Law from Theory, vol. 1, China Founder's Press, 1999, p. 15. 